\title{
HUBUNGAN KELINCAHAN DENGAN KETERAMPILAN DRIBBLING BOLA BASKET PADA SISWA KELAS VIII SMP NEGERI 43 PALEMBANG
}

\author{
Helen Purnama Sari \\ Email : $\underline{\text { Helenpurnamasari20@gmail.com }}$ \\ Universitas Islam Kalimantan MAB Banjarmasin
}

\begin{abstract}
This study entitled Relationship of agility with basketball dribbling skills at students of Junior hight school 43 Palembang state, the purpose of this study was to determine the relationship of agility with basketball dribbling skills at students of Junior hight school 43 Palembang state. The method used in this study is the Correlation research method. This research is a type of associative research by looking for the relationship between agility of the body towards the ball dribbling skills in basketball games. The research variable is everything in the form that is determined by the researcher to be studied so that information about it is obtained, then conclusions are drawn, samples in the study there are 25 students. To process the test results, statistical steps are used which are guided by the product moment correlation formula with 1 . Test the correlation coefficient, 2. Significance test, 3. Determination test.

The results of this study are from the calculation results show that the relationship or correlation coefficient between agility (X) and dribbling skills (Y) is rxy $=0.725$. To see the strength of the relationship between the two variables, the authors refer to the guidelines made by Sugiyono (2012: 231) where the value of 0.725 in the interval between $0.60-0.799$ which states that the relationship between the two variables is strong and Based on existing calculations, then $\alpha=0.05$ and $n=23$, two-party test $d k=n-2=$ $25-2=23$ so that $\mathrm{t}$ table $=1.714$ is obtained. It turns out that tcount is greater than $\mathrm{t}$ table, or 5.0484> 1.714. Then Ho is rejected, meaning that there is a significant relationship between the relationship of agility with ball dribbling skills at students of Junior hight school 43 Palembang state.
\end{abstract}

Keyword : Basketball, Agility, Dribbling skills. 


\section{PENDAHULUAN}

Olahraga adalah satu bidang yang mendapatkan perhatian penuh dari pemerintah Indonesia, terutama untuk meningkatkan kualitas manusia Indonesia yang sehat jasmani dan rohani, menjunjung tinggi nilai-nilai sportifitas, disiplin dan bertanggung jawab. Seperti yang tertera dalam Himpunan peraturan perundang-undangan tahun 2008 tentang sistem Keolahragaan Nasional halaman 7 pasal 4 tentang dasar, fungsi dan tujuan olahraga yaitu meningkatkan dan memelihara kesehatan dan kebugaran jasmani, prestasi, membina persatuan dan kesatuan bangsa, memperkukuh ketahanan nasional serta harkat, martabat dan kehormatan bangsa.

Semua negara berupaya meningkatkan prestasi olahraganya untuk dapat berbicara dalam kejuaraan nasional maupun internasional, dimana dengan prestasi olahraga nama bangsa dapat menjadi lebih baik. Untuk itu prestasi olahraga suatu bangsa menjadi perhatian yang besar dalam program pembangunan bangsanya, contohnya Indonesia dengan emasnya untuk persiapan SEA GAMES tahun 2011 di Indonesia.

Pendidikan Jasmani di Sekolah mempunyai peran unik dibanding dengan bidang studi lain, karena melalui penjas orkes selain dapat digunakan untuk pengembangan aspek fisik dan psikomotor juga ikut berperan dalam pengembangan aspek kognetif dan afektif secara serasi dan seimbang.Pendidikan jasmani olahraga dan kesehatan sebagai bagian integral dari proses pendidikan secara keseluruhan.

Untuk meningkatan daya sumber manusia Indonesia sebagai kekayaan yang kekal dan investasi untuk mencapai kemajuan bangsa, peningkatan mutu pendidikan dasar berlaku menyeluruh termasuk di dalamnya adalah pendidikan jasmani di sekolah. Salah satu tujuan dari pembinaan dan pengembangan olahraga di sekolah adalah meningkatkan prestasi, maka untuk dapat meningkatkan prestasi siswa hendaknya ditempuh melalui pendekatan secara ilmiah. Sebab pada dasarnya seorang calon juara yang berbakat harus ditolong kehadirannya bahkan memerlukan asuhan, pembinaan maupun pengarahan untuk dapat mengembangkan dan mencapai prestasi puncak.

Sekolah merupakan tempat yang fungsional dalam rangka mengembangkan pelajaran baik yang bersifat fisik maupun yang berkaitan dengan jiwa atau rohani. Pendidikan jasmani sangat penting dalam dunia pendidikan karena selain bertujuan untuk kebugaran 
jasmani, juga bertujuan untuk membentuk kepribadian yang luhur. Karena pendidikan jasmani merupakan proses pendidikan tentang dan melalui aktifitas jasmani, permainan atau olahraga terpilih untuk mencapai tujuan pendidikan. Pendidikan merupakan suatu kebutuhan yang sangat penting bagi manusia, karena dengan pendidikan manusia dapat mencapai kesejahteraan hidupnya. Pendidikan sangat berguna untuk menunjang pertumbuhan dan perkembangan dalam segala bidang, terutama untuk mengembangkan dan menjamin kelangsungan hidup bangsa.

Olahraga basket ini sudah sangat dikenal oleh kalangan dewasa apalagi kalangan anak muda, permainan ini merupakan permainan yang sangat diminati dan menarik perhatian para generasi muda khususnya para anak-anak dan pelajar, mereka sudah mengenal permainan basket bahkan ada yang sampai berlatih khusus untuk menguasai teknik-teknik dasar dan seluruh yang mengcangkup permainan bola basket. Terbukti dengan adanya berbagai pertandingan bola basket mulai dari antar sekolah, antar daerah,antar provisinsi, nasional bahkan sampai kepertandingan Internasional. Ini cukup membuktikan bahwa minat masyarakat begitu antusia terhadap bola basket.

Peneliti sempat melakukan observasi dan sedikit wawancara di SMP N 43 Palembang, peneliti mengamati banyak cabor yang diikuti oleh para siswa di sekolah tersebut dan peneliti dapat menyimpulkan bahwa olahraga basket lah yang paling banyak digemari oleh siswa-siswa di SMP N 43 Palembang. Saat peneliti melakukan kegiatan praktek kerja lapangan, peneliti melihat permainan bola basket siswa di SMP tersebut masih kurang baik, apalagi saat siswa tersebut membagi kelompok dan bermain games. Bola masih sangat cepat diambil lawan dan sering kali bola tersebut sulit dikuasi dan memantul di area lain bahkan keluar lapangan permainan basket. Oleh karena itu peneliti merasa tertarik untuk meneliti lebih jauh dan diduga teknik kelincahan lah yang dapat dijadikan salah satu solusi sehingga peneliti tertarik untuk mempelajari secara metode:"Hubungan kelincahan dengan keterampilan dribbling bola basket pada siswa kelas VIII SMP N 43 Palembang"

\section{TINJAUAN TEORITIS}

Permainan bola basket merupakan salah satu cabang olahraga yang banyak digemari oleh masyarakat pada umumnya. Permainan bola basket dikenal sebagai olahraga yang dinamis dan aktraktif, karena menuntut suatu kombinasi kemampuan fisik dan keterampilan teknik yang berkualitas. 
Bola basket dimainkan hampir semua sekolah lanjutan untuk anak laki-laki. Bahkan anak-anak wanita juga ikut main. Disekolah menengah juga tampak kecenderungan untuk bermain basket dengan semakin berkembangnya mini basket, anak-anak sekolah dasar pun sudah bisa mengikuti permainan ini. Dalam olahraga basket ini. Seperti kita lihat, anak-anak dapat belajar lari, melompat, menangkap, mengoperkan dan memasukkan bola ke keranjangnya. Selain itu juga belajar mengubah arah dan kecepatan, yang merupakan dasar untuk mengembangkan diri di bidang olahraga manapun juga kelak.

Kelincahan adalahMenurut Dedy Sumiyarsono (2006:91) "Kelincahan (agility) adalah kemampuan seseorang untuk berlari cepat dengan mengubah-ubaharahnya. Sedangkan menurut Wahjoedi (2001:61) kelincahan adalah kemampuan tubuh untuk mengubah arah secara cepat tanpa adanya gangguan keseimbangan atau kehilangan keseimbangan, kelincahan memiliki peranan yang sangat penting dalam permainan bola basket terutama dalam menghindari sergapan lawan pada saat melakukan dribbling maupun digunakan untuk memasukkan bola ke gawang lawan, sehingga mendapat angka dan kemampuan tubuh mengiluk-liuk menghindari sergapan lawan sangat di perlukan oleh pemain basket.

Menggiring bola adalah cara untuk bergerak dengan bola yang dilakukan oleh seorang pemain dengan memantul-mantulkan bola di area lapangan bola basket saat melakukan dribble pemain akan menjaga bola tetap berada disisi tubuhnya untuk melakukan nya bola didorong pelan kebawah dengan kondisi jari tangan terbuka untuk melakukan control ketinggian juga ketepatan saat menggiring bola jika tetap menahan tangan diatas bola maka bola akan memantul kembali ke tangan dengan akurat. (PERBASI, 2006:18)

Menurut Salim (2005: 47) mengiring bola basket atau dribbling adalah gerakan memantul-mantukankan bola secara terus menerus dengan menggunakan satu tangan yang berkontak pada bola. Pergantian tangan boleh dilakukan, tetapi dribel dengan menggunakan dua tangan tidak diperbolehkan. Dribbling atau menggiring bola berakhir saat bola berhenti pada satu tangan, dan kalian tidak diperbolehkan untuk melakukan dribel kembali sebelum bola menyentuh tangan pemain lain. Kalian harus tetap memantulkan bola saat menggiringnya. Jika seorang wasit berpendapat atau melihat bahwa kalian membawa bola dengan cara yang lain (tanpa memantulkannya ke lantai), maka akan dikenai hukuman.

Dribble di lakukan dengan kekuatan siku, pergelangan tangan jari- jari, sedikit bantuan dari bahu, jari harus selalu rileks namun tegas menekan bola.Berdasarkan 
pengertian dribbling yang dikemukakan oleh beberapa ahli tersebut peneliti dapat menyimpulkan bahwa, dribble merupakan suatu cara membawa bola ke depan dengan memantul-mantulkan bola ke lantai dengan satu tangan atau secara bergantian baik dengan berjalan atau berlari. Hal terpenting dan harus diperhatikan dalam melakukan dribble adalah melindungi bola agar bola tidak mudah direbut lawan. Seperti dikemukakan Wissle (2000: 95) bahwa "Kemampuan mendribble dengan tangan lemah dan tangan kuat adalah kunci untuk meningkatkan permainan anda. Untuk melindungi bola, jagalah agar tubuh anda berada diantara bola dan lawan”.

Dalam melakukan dribble tubuh mempunyai peran penting jika tangan yang digunakan mendribble lemah, maka tubuh berfungsi untuk melindungi bola. Oleh karena itu, pada saat mendribble bola, tubuh harus selalu diantara bola dan lawan. Hal ini dimasukkan, Jika lawan akan merebut bola maka tubuh siap untuk menghalangi lawan.

\section{METODOLOGI}

Metode penelitian adalah cara yang digunakan oleh peneliti dalam mengumpulkan data penelitiannya (Suharsimi,2006:160). Metode yang digunakan dalam penelitian ini adalah metode penelitian Korelasi. Penelitian ini adalah jenis penelitian Assosiatif dengan mencari hubungan antara kelincahan gerak badan terhadap meterampilan dribbling bola pada permainan bola basket. variabel penelitian adalah segala sesuatu yang berbentuk apa saja yang ditetapkan oleh peneliti untuk dipelajari sehingga diperoleh informasi tentang hal tersebut, kemudian ditarik kesimpulannya."

Berdasarkan pendapat di atas, maka yang menjadi titik perhatian dan variabel yang ditetapkan dalam penelitian ini adalah :3.2.1. Variabel bebas (X)Sebagai variabel bebas dalam penelitian ini adalah kelincahan.3.2.2. Variabel Terikat (Y) Sebagai variabel terikat dalam penelitian ini adalah keterampilan dribbling bola pada permainan bola basket.Jumlah Populasi pada penelitian ini adalah seluruh siswa laki-laki kelas VIII yang berjumlah 126 siswa Sampel adalah sebagian atau wakil populasi yang diteliti Suharsimi (2006:131). Apabila kurang dari 100 lebih baik diambil semua sehingga penelitiannya merupakan penelitian populasi. Tetapi jika jumlahnya subjeknya besar, dapat diambil antara 10\%-15\% atau 20\%-25\% atau lebih. Jadi dari penjelasan di atas maka peneliti akan mengambil sampel 20\% dari jumlah populasi sehingga berjumlah 25siswa untuk diteliti, dengan ini penelitain yang peneliti lakukan adalah penelitian populasi. 
Dalam pengumpulan data pada penelitian ini menggunakan penjelasan(ceramah) dimana peneliti menjelaskan terlebih dahulu apa yang dimaksud dengan dribbling dan kelincahan serta jenis-jenis kelincahan, kemudian penelitian ini menggunakan tes Dalam penelitian ini, peneliti menggunakan teknik data statistik dengan metode korelasi product moment.

Untuk mengolah hasil tes maka digunakan langkah-langkah statistik yang berpedoman pada rumus korelasi product moment. Langkah-langkahnya adalah sebagai berikut : 1 . Uji koefisien korelasi, 2. Uji signifikansi, 3. Uji Determinasi

\section{PEMBAHASAN}

Penelitianiniberjudulhubungan kelincahan dengan keterampilan dribbling bola pada permainan bola basket siswa kelas VIII SMP Negeri 43 Palembang Setelah data terkumpulmelaluiteskelincahandenganmenggunakaninstrumenZig-zagRun dan keterampilandribblingdenganmenggunakanistrumenZig-

zagDribbling. Makauntukmemberikan gambaran umummengenaidistribusi data yang diperolehdarilapanganpenelitimendeskripsikanpenelitianinimeliputinilaiterendah, nilaitertinggi dan rata-rata. Berikutinimengenai data-data selengkapnya:

\section{Tabel. Deskripsi data penelitian}

\begin{tabular}{|l|l|l|}
\hline Variabel & Kelincahan & $\begin{array}{l}\text { Keterampilan } \\
\text { Dribbling }\end{array}$ \\
\hline $\begin{array}{l}\text { Nilai } \\
\text { tertinggi }\end{array}$ & 25 & 14 \\
\hline $\begin{array}{l}\text { Nilai } \\
\text { terendah }\end{array}$ & 13 & 10 \\
\hline Rata-rata & 19,64 & 12,01 \\
\hline
\end{tabular}


Volume 4 Nomor 2, Oktober 2018

Dibawah ini disajikan mengenai distribusi frekuensi dan grafik histrogram kelincihan (X)

Tabel Distribusi Frekuensi variabel kelincahan

\begin{tabular}{|l|l|l|}
\hline $\begin{array}{l}\text { Kelas } \\
\text { interval }\end{array}$ & $\begin{array}{l}\text { Frekuensi } \\
\text { absolute }\end{array}$ & Frekuensi relative (\%) \\
\hline $13-15$ & 2 & $8 \%$ \\
\hline $16-18$ & 7 & $28 \%$ \\
\hline $19-21$ & 9 & $36 \%$ \\
\hline $22-24$ & 6 & $24 \%$ \\
\hline $25-27$ & 1 & $4 \%$ \\
Jumlah & 26 & $100 \%$ \\
\hline
\end{tabular}

Dibawah ini disajikan mengenai distribusi frekuensi dan grafik histrogram kelincihan (X)

\begin{tabular}{|l|l|l|}
\hline $\begin{array}{l}\text { Kelas } \\
\text { interval }\end{array}$ & $\begin{array}{l}\text { Frekuensi } \\
\text { absolute }\end{array}$ & Frekuensi relative (\%) \\
\hline $10-11$ & 9 & $36 \%$ \\
\hline $12-13$ & 12 & $48 \%$ \\
\hline $14-15$ & 4 & $16 \%$ \\
\hline $16-17$ & 0 & $0 \%$ \\
\hline $18-19$ & 0 & $0 \%$ \\
\hline Jumlah & 25 & $100 \%$ \\
& & \\
\hline
\end{tabular}

\section{Uji Hipotesis}

Setelah peneliti mengemukakan hasil penelitian berdasarkan variabel masing-masing, untuk langkah selanjutnya peneliti akan melakukan pengujian hipotesis dengan memasukkan nilai-nilai dari variabel X dan Y kedalam rumus Product Moment.

Maka peneliti dapat membuktikan apakah menerima hipotesis alternatif (Ha) atau menolak hipotesis nol (Ho). Untuk lebih lanjut dapat dilihat pada tabel kerja dan perhitungan dibawah ini. 
Volume 4 Nomor 2, Oktober 2018

Langkah - langkah yang perlu diambil :

Menjumlahkan subjek penelitian $\mathrm{N}=25$.

Menjumlahkan skor variabel $\mathrm{X}$, diperoleh $\sum \mathrm{X}=468$

Menjumlahkan skor variabel $\mathrm{Y}$, diperoleh $\sum \mathrm{Y}=301$

Mengalirkan skor variabel X dan skor variabel Y (yaitu : XY), setelah selesai lalu di jumlahkan, diperoleh $\sum X Y=5922$

Mengkuadratkan skor variabel X (yaitu : ) dan setelah selesai lalu dijumlahkan, diperoleh $\sum=9658$

Mengkuadratkan skor variabel Y (yaitu : ) dan setelah selesai lalu dijumlahkan, diperoleh $\sum=3669$

Jadi koefisien korelasi perhitungan adalah sebesar 0,725

Dari hasil perhitungan diatas menunjukkan bahwa besar hubungan atau koefisien korelasi antara kelincahan (X) dengan keterampilan dribbling (Y) adalah $r_{x y}=0,725$ Untuk melihat kekuatan hubungan antara kedua variabel, penulis berpatokan pada pedoman yang dibuat oleh Sugiyono (2012 : 231) dimana nilai 0,725 dalam interval antara 0,60 - 0,799 yang menyatakan bahwa hubungan antara kedua variabel yaitu kuat. Selanjutnya untuk mencari taraf signifikan antara hubungan kelincahan dengan keterampilan dribbling bola pada siswa kelas VIII SMP Negeri 43 Palembang

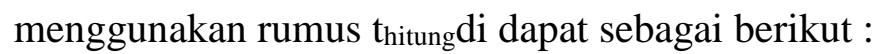

$\mathrm{t}=5.0484$ 
Untuk kaidah pengujian, jika $\mathrm{t}_{\text {hitung }}>\mathrm{t}_{\text {tabel}}$, maka tolak Ho artinya terdapat hubungan yang signifikan dan jika $t_{\text {hitung }}<\mathrm{t}_{\text {tabel, }}$, terima Ho artinya tidak terdapat hubungan yang signifikan.

Berdasarkan perhitungan yang ada, maka $\alpha=0,05$ dan $\mathrm{n}=23$, uji dua pihak $\mathrm{dk}=$ $\mathrm{n}-2=25-2=23$ sehingga diperoleh $\mathrm{t}_{\text {tabel }}=1.714$.

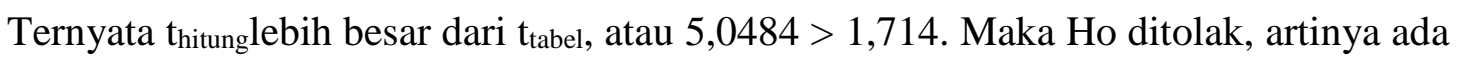
hubungan yang signifikan antara hubungan kelincahan dengan keterampilan dribbling bola pada permainan bola basket siswa kelas VIII SMP Negeri 43 Palembang.

Kemudian dapat diketahui koefisien determinasi dengan cara mengalihkan koefisien korelasi yang dikuadratkan dengan 100\% dimana koefisien korelasi yang dilambangkan dengan $\mathrm{r}$ adalah 0,725 dikuadratkan kemudian dikalihkan $100 \%$ sehingga diperoleh koefisien determinasinya sebesar $52,56 \%$.

\section{SIMPULAN}

Berdasarkan hasil penelitian, analisis data, dan pembahasan yang telah dilakukan, dapat diambil kesimpulan sebagai berikut :

Terdapat hubungan yang kuat antara kelincahan dengan keterampilan dribbling bola pada permainan bola basket siswa kelas VIII SMP Negeri 43 Palembang. Hasil ini diketahui berdasarkan uji hipotesis didapat nilai rxy sebesar 0,725 yang berarti adanya hubungan yang kuat antara kelincahan dengan keterampilan dribbling bola.

Terdapat hubungan yang signifikan antara kelincahan dengan keterampilan dribbling bola pada permainan bola basket siswa kelas VIII SMP Negeri 43 Palembang dari hasil uji signifikansi diperoleh $t_{\text {hitung }} \quad 5,0484 \geq t_{\text {tabel }}$ 1,714.Berdasarkan koefisien determinasinya kelincahan memberikan kontribusi yang besar terhadap keterampilan dribbling bola sebesar $52,56 \%$ yang berarti masih ada variabel lain yang memberikan kontribusi terhadap keterampilan dribbling bola sebesar $47,44 \%$. 


\section{SARAN}

Untuk mendapatkan hasil yang maksimal dalam melakukan dribbling, disarankan bagi pelatih / guru untuk dapat memberikan latihan kelincahan secara teratur, terprogram, dan berkesinambungan agar dapat menambah kemampuan dribbling dan dapat memperoleh hasil yang maksimal dari keterampilan dribbling itu sendiri contoh nya latihan Zig-zag Run, Shuttle Run, Dogging Run, LSU Agility.Disamping hal tersebut, perlu dilatih pula teknik dalam melakukan dribbling yang baik mulai dari posisi tubuh sebelum dan saat melakukan gerakan dribbling, posisi kaki, tangan dan gerakan yang melakukan dribbling secara mendalam.Bagi sekolah hendaknya memenuhi kebutuhan fasilitas sarana dan prasarana yang diperlukan dalam latihan seperti lapangan olahraga yang baik, bola, ring, tiang ring yang sesuai standar, net dan peralatan olahraga lainnya khususnya untuk ekstrakurikuler bola basket di SMP Negeri 43 Palembang agar menjadi bahan pendukung untuk meningkatkan prestasi serta keterampilan para siswa yang mengikuti kegiatan belajar permainan bola basket maupun yang ikut ekstrakurikuler khusus bola basket.Bagi peneliti selanjutnya yang ingin melakukan penelitian sejenis, hendaknya mengambil permasalahan yang berbeda sehingga diharapkan memperoleh hasil penelitian yang lebih baik.

\section{DAFTAR PUSTAKA}

Arikunto, Suharsimi. 2010. Prosedur Penelitian. Jakarta : Rineka Cipta Amber, VIC. 2009. Bola basket. Bandung: Pionir Jaya

Dwiyogo, Wasis. 2010. Penelitian Keolahragaan. Malang :Universitas Negeri Malang Margono, Dedi. 2010. Permainan Bola Baket. Surakarta : UPT Penerbitan

Nurhasan. 2001. Tes dan pengukuran. Jakarta : Direktorat Jendral Olahraga

PERBASI. 2006. Bola basket untuk semua. Jakarta : JMR

Salim, Agus. 2005. Buku Pintar bola basket. Bandung.

Sugioyono. 2012. Metode penelitian kuantitatif, kualitatif dan R\&D. Jakarta : Alfabeta

Wissel, Hal. 1999. Bola Basket. Jakarta : PT Raja Grafindo Persada

Wahjoedi, 2001. Landasan evaluasi pendidikan jasmani. Jakarta : PT Raja Grafindo Persada 